\title{
On the Characteristics of Scientific Discourse and Translation
}

\author{
Minggao Wei \\ College of Foreign Languages, University of Shanghai for Science and Technology, Shanghai, China \\ Gaofeng Yu \\ College of Foreign Languages, University of Shanghai for Science and Technology, Shanghai, China
}

\begin{abstract}
The process of translation is essentially to recognize and reconstruct the textual coherence, and to a large extent, the reestablishment of textual coherence and the success of communicative function of translation attribute to the corresponding translation strategy. Illustrated by examples, this paper discusses some appropriate translation strategy in scientific discourse translation.
\end{abstract}

Index Terms - scientific discourse; textual characteristic, translation

\section{INTRODUCTION}

Text refers to any natural language unit that is not bound by complete sentence grammar and has communicative function in a specific context and represents complete semantics. Text linguistics was first put forward by Linguist of Germany scientist Weinrich in 1967. Since then, text linguistics has gradually been accepted by people and attracted more and more linguists' attention. The famous Dutch psycholinguist Teun van Dijk) (1979) pointed out that discourse linguistics actually does not refer to a certain theory or a certain research method, but refers to any research that takes discourse as its research purpose. In their book Introduction to Text Linguistics, de Beau Grande and Dressler introduced seven standards of text linguistics in detail: cohesion, coherence, intention, Acceptability, informality, situation and intertextuality have established the important position of cohesion and coherence in text linguistics. Of these seven standards, "cohesion" and "coherence" are undoubtedly the most important, because cohesion and coherence are the basis of other standards, and other standards need to be analyzed and studied on the basis of cohesion and coherence. Cohesion is an important feature of a text, which is mainly reflected in the surface structure of the text. Lexical and grammatical means can be reflected in structural cohesion, that is, structural cohesion. It can be said that cohesion is the tangible network of a text. Coherence is the main feature of a text. It refers to the semantic connection in a text. Coherence exists at the bottom of the text and achieves semantic connection through logical reasoning. Therefore, coherence is an invisible network of discourse.

The so-called discourse refers to any natural language unit that is not constrained by complete sentence grammar, has communicative function in a specific context, and represents complete semantics (Yu, 2009, p47-51). Text is not a combination of simple sentences, but a whole with internal logical structure, expressing a complete meaning. From the perspective of linguistic form and semantic logic, there is a certain cohesion between paragraphs and even between sentences in a text. The whole text has its beginning and end. The concepts or propositions reflected in each paragraph are consistent rather than irrelevant (Zou, 2003, p.32-34). Therefore, in translation, the translator should not focus on the surface of the sentence, but should carefully analyze and understand the meaning of the text, think about the source text as a whole, carefully and reasonably consider and analyze the source text within the framework of the text, so that the translated text can fully reflect the meaning of the source text (Hu, Zhu \& Zhang, 1988).

Currently, high technology, especially information technology, has been widely popularized all over the world, and international economic and technological exchanges are booming. People urgently need to understand the information and the advanced scientific knowledge of advanced countries through the translation of scientific texts. Translation speed has also become increasingly important and urgent. Therefore, to fully understand the characteristics of EST texts and to master their translation methods should be the principle that translators should grasp as soon as possible. Based on this, this paper will discuss some cohesion and coherence strategies in the translation of scientific and technological texts according to Halliday's theory of cohesion and coherence, with a view to contributing to the translation practice of scientific and technological texts.

\section{COHESION AND COHERENCE IN TEXT AND THEIR RELATIONS}

Systemic functional linguistics is the first time to raise language research from the traditional level of words and sentences to the level of discourse, which is a significant contribution to linguistic research. At present, discourse analysis already enjoys popular support in the people. The textual function of systemic functional linguistics can be said to be its essence. The functional part of the text includes three subsystems, namely, thematic-rheme system, known 
information-new information system and cohesion system (Liu, 2004, p.28-32).

The concept of cohesion was first proposed by Halliday in 1962. In 1976, he and Hasan co-authored the book Cohesion in English (1976), which can be said to be the symbol of the creation of cohesion theory. The book points out that cohesion is a semantic concept, which refers to the semantic relationship between linguistic components that exist in a text and enable the text to exist. Cohesion can generally be divided into lexical cohesion, conjunction, reference, substitution, etc. In text translation, it is necessary to fully understand the cohesive devices and methods in the original text, so that the translation can reflect the cohesive methods of the original text as much as possible. Sometimes, the cohesive devices and methods can be changed in the translation to achieve the same effect as the original text. In text translation, understanding and grasping textual cohesion will directly affect the quality of the translation.

Coherence is a textual feature that words, clauses and sentence groups are conceptually, logically and properly connected. A coherent text has an internal logical structure that runs through the whole text from beginning to end, connecting all concepts together organically, so as to achieve the effect of clear temporal and spatial sequence and logical progression with distinct levels (Beau, Robert \& Dressler, 1981). It can be said that coherence is an invisible network of discourse, and semantic coherence is an important symbol of discourse. Translators can only convey the theme and function of the original work if they can see clearly and fully the inner-sentence, inter-sentence or inter-paragraph relationships that seem to be independent of each other and actually refer to each other. The problems of discourse coherence are mainly manifested in logic reorganization, promotion level and transformation of narrative thinking. Correctly handling these problems is an essential condition to ensure the semantic coherence of the translated text. Otherwise, the translated text will be messy, confused and even mistranslated.

\section{TYPES OF COHESION}

Cohesion means that all parts of a paragraph are related in grammar or vocabulary or both. This connection may exist between different sentences or between parts of a sentence. Cohesion is an important feature of discourse, which distinguishes the piling up of incoherent and unsystematic sentences. The quality of cohesion is related to the topic of the discourse or whether the information is understood and accepted by the recipient. Cohesion can generally be divided into lexical cohesion, conjunctions, anaphora, substitution and ellipsis. In text translation, it is necessary to fully understand the cohesive devices and methods in the original text, so that the translation can reflect the cohesive methods of the original text as much as possible. Sometimes, the cohesive devices and methods can be changed in the translation to achieve the same effect as the original text. In text translation, understanding and grasping textual cohesion will directly affect the quality of the translation.

\section{A. Lexical Cohesion}

Lexical cohesion can be divided into five categories: repetition, general words, similarity, classifiable and collocation (Hu, 1994, p.112). Lexical cohesion refers to the means by which words are used to achieve textual cohesion. Since the meaning and usage of many words in English and Chinese are not one-to-one equivalent, in translation practice, we must first find out the lexical cohesion in the original text and find out the corresponding translated words in order to make the translated words appropriate and reasonable.

Example 1: Four months before Election Day, five men gathered in a small conference room at the Reagan-Bush headquarters and reviewed an oversized calendar that marked the remaining days of the 1984 presidential campaign. It was the last Saturday in June and at ten o'clock in the morning, the rest of the office was practically deserted. Even so the men kept the door shut and the drapes carefully drawn.

Translation: 离大选还有四个月, 里根一布什总部的一间小会议室里聚集了五个人, 他们审视着一份标有 198 年总统竞选活动所剩日期的巨型日历。那是六月份最后一个星期六, 早晨十点钟, 办公室里实际已没有其他人。 尽管如此，这几个人还是把门关好，还小心翼翼地拉上窗帘(Li, 2001, p.134)。

The translation of the word office into "办公室" is absolutely correct in terms of the surface meaning of the word, but it seems inaccurate and unreasonable in terms of textual cohesion. Because, there is no one else in the same office, who should close the door and draw the curtains to prevent? Apparently, someone outside the office. The main source of this problem lies in the translator's failure to understand the cohesion of the word office in the original text. In fact, office and headquarters here form the cohesion of the upper and lower words, that is to say, office refers to headquarters. After understanding the cohesion of this word, it is obvious that office should be translated as: there is actually no other person in the headquarters.

\section{B. Connective Words}

Linking words refer to certain words in the original text that play a connecting role in the whole text. In translation, sentences and sentences, paragraphs and paragraphs should be connected in a very organized way through certain cohesive devices, so that the whole text forms a complete or relatively complete semantic unit.

Example 2: "There's certainly too much pepper in that soup!" Alice said to herself, as well as she could for sneezing. There was certainly too much of it in the air. Even the Duchess sneezed occasionally; and as for the baby, it was sneezing and howling alternatively without a moment's pause. The only two creatures in the kitchen that did not sneeze, 
were the cook, and a large cat ...

Translation: “我看那汤里的胡椒一定搁得太多啦！”爱丽丝说着就觉得要打喷嚏。

实在那空气当中的胡椒面儿是不少。连那公爵夫人自己也有时候打喷德; 要说那个小孩, 那就不是打喷德就 是叫, 不是叫就是打喷德。那厨房里只有两个不打喷德的, 一个就是那个做饭的老妈子, 一个是只大猫....... (赵 元任译)

In this example sentence, the translator has strengthened the cohesion between the sentence and the sentence, between the paragraphs and within the paragraphs, making the context of the whole text smooth, and has made wonderful treatment of some words with connecting function. For instance, in order to make the semantics between paragraphs more closely linked, certainly is translated as "reality" and placed at the beginning of the sentence; even and as for are translated as usual as "even ..." and "to say". To translate alternative without a moment's pause into "either ... or"; two only creatures are translated as "one ... one", which better meets the needs of elaboration.

\section{Anaphor}

Anaphora is a common cohesive device used in English and Chinese. However, due to the differences in expression habits and modes of thinking, translation should not be limited to the structure and anaphoric relationship of the original text, and word-by-word translation should be carried out. Different treatment methods of anaphora in the original text and the translated text should be found and some appropriate adjustments should be made. Anaphora is usually divided into personal anaphora, indicative anaphora, comparative anaphora and clause anaphora. As far as English-Chinese translation practice is concerned, personal reference and indicative reference are the most theoretical discourse phenomena. In translation, to recognize the relationship between personal reference, in many cases, pronouns in English must be reduced to Chinese nouns and expressed clearly.

\section{FEATURES OF SCIENTIFIC ENGLISH TEXTS}

Due to people's different social activities, different discourses have different linguistic features. Scientific English discourse is different from non-standard discourses such as novels and poems. It belongs to a very formal language, which is determined by its ideographic function, textual function and interpersonal function. Scientific English discourse includes scientific writings, scientific papers, experimental reports, scientific and technological information materials, introduction of scientific and technological trends and operating procedures of experiments, etc. The remarkable feature of EST discourse is that it attaches great importance to the coherence of narrative logic and the clarity of expression, and accurately expresses scientific facts through its strict logic and objective description (Ren, 2009, p.124-126). There is also a clear pattern in the text structure of scientific and technological texts, and the language program and style are basically unchanged. Therefore, the first thing that should be paid attention to in the translation of scientific and technological texts should be the information conversion between the two languages. The important principle of translation should be to be faithful to the original meaning, that is, to preserve the stylistic features of the original text and the translated text and to pay attention to their consistency. In addition, translation also requires clear concepts, clear logical relations, accurate data and concise and clear text.

\section{Coherence Strategies in Translation of Scientific TeXts}

In the translation of scientific English, due to the differences in morphology, syntax and cohesion between English and Chinese, as well as their different ways of thinking and expression, the equivalence translation between the source language and the target language cannot be completely carried out. This requires the translator to make corresponding modifications in the process of translation, and at the same time to construct the translated text according to the original author's intention and in combination with the logical relations and structural methods of the text. In other words, the translator must establish a strong discourse awareness in the translation practice. He must look at and organize the translation from a dynamic perspective, so that the translation conforms to the expression habits and laws of Chinese, the meaning is clearer and clearer, the semantics are complete, and the language expression is natural and smooth. In order to meet these requirements, corresponding translation strategies should be adopted in translation practice. The following is the author's analysis of some common coherence strategies in the translation of scientific texts.

\section{A. Adding Necessary Words}

Due to the differences between English and Chinese, we need not expect the translation to be consistent with the original, but should make reasonable additions to the translation according to the habitual expression of Chinese. The so-called additional translation is to add necessary words, phrases, clauses or complete sentences to the original text, so as to make the translation conform to the expression habits of Chinese in grammar and language form and keep the translation consistent with the original text in rhetoric, grammatical structure, meaning or tone, so as to make the translation more accessible and smooth. Incremental translation is one of the translation methods frequently used in EST translation.

Example 1: Engineers predict that integrated optical circuits will follow the same dramatic trends that have driven semiconductor electronics over the past two decades: they will become smaller, faster and cheaper. 
Translation: 工程师们预言, 集成光路将按照过去二十年间促使半导体电子学高速发展的速度发展：其体积 将更小、速度更快、造价更低。

In the original text, three adjectives "small, faster and cheaper" are used to describe the characteristics of the future integrated optical path clearly without any restrictive words, which is determined by the characteristics of the original language. In order to make the translation more in line with the Chinese expression habits, the translator has added three words "volume, speed and cost" to the translation, which makes the translation properly connect the semantic relations before and after the sentence and helps readers to read and understand the original text smoothly.

\section{B. Repeat Key Words}

Although English and Chinese belong to different language families, human beings live in the same material world, and their thinking patterns have certain consistency, and their thinking contents also have similarities. From the perspective of discourse, they also have similarities in lexical cohesion. Therefore, in translating English into Chinese, the cohesive devices of the source language can be repeated to achieve textual equivalence and coherence.

Example 2: In general, drying a solid means the removal of relatively small amount s of water or other liquid from the solid material to reduce the content of residual liquid to an acceptably low value.

Translation : 一般来讲, 干燥一种固体指的是从固体材料中除去相对少量的水或其他液体, 从而使残留液体 的含量减少到可接受的低值。

The repetition of "solid" and "liquid" in the source text makes the whole text closely connected and explains accurately and clearly to the reader how to " dry a solid" procedure. The translation also grasped the two key words " solid" and " liquid" and repeated them accordingly, successfully reproducing and retaining the cohesion of the original text and achieving the effect intended by the original text.

\section{Replacement}

English texts are concise and avoid repetition. Therefore, pronouns are often used in English texts to replace the same parts as before. In order to avoid confusion and misunderstanding in Chinese translation, the corresponding nouns referred to by pronouns are sometimes repeated to make the translation clearer and clearer.

Example 3: There are two boxes inside the boiler, an inner one and an outer one, which extend a long forward.

Translation: 锅炉有两个火箱, 一个内火箱，一个外火箱。这两个火箱都向前延伸很长一段距离。

In the original text, one and which were used to replace the boxes in the previous text respectively, which is in line with the English expression habit. In order to make the translation clearer and more accurate, the nouns they refer to are restored in the translation, and noun repetition is adopted, which conforms to the expression habits of Chinese.

\section{Ellipsis}

Some ellipsis often occurs in English texts. The purpose of context cohesion is achieved by omitting certain words. Ellipsis is a coordination between conciseness and clarity. Ellipsis is usually divided into nominal ellipsis, verb ellipsis and clause ellipsis. In translation, it is often necessary to reproduce the omitted words in the original text so as to make the expression of the translated text more accurate and fluent and conform to the expression habits of Chinese.

Example 4: When try to decide whether an object will float in water, you need to know whether its density is greater or less than that of water. If it is greater (than that of water), the object will sink, if (it is) less (than that of water), it will float.

Translation: 如果要测定一个物体能否浮在水面, 就需要清楚它的密度比水的密度大还是小。如果密度比水大, 那么物体就会下沉。如果密度比水小，那么物体就会漂浮在水面。

The boldface text with brackets in the original text is the omitted part. Although there is omission, its meaning is very clear and definite. It also avoids the encumbrance of language use and makes the whole text more concise. However, in translation, these omitted parts need to be restored, otherwise, the translation will appear unclear and lack coherence.

\section{E. Thematic and Rheme Translocations}

Thematic progression has a very important influence on discourse coherence. English science and technology texts usually use the same thematic progression mode to develop texts, while Chinese science and technology texts tend to use the same thematic progression mode to promote texts. Therefore, in translation, we must not blindly pursue formal equivalence with the original text, but make clear the information structure of the original text, clarify the author's thinking, and make necessary adjustments according to the needs of the translation, so as to achieve maximum functional equivalence.

Example 5: The smaller particulates are called aerosols. The largest aerosols are just visible with a good microscope. Examples are the finer components of tobacco smoke, insect dusts, and larger viruses.

Translation: 较小的颗粒物叫气溶胶。香烟烟雾的微粒、杀虫剂的粉末和大的病毒是最大的气溶胶，可用高 分辨率的显微镜进行观察。

The translation does not follow the sequence of the source text, but integrates the two or three sentences into one sentence, and puts the content of the third sentence before the second sentence, which makes the translation appear more compact, clearer in logic and achieves very good results. 


\section{F. Information Structure}

In scientific English discourse, important information is often highlighted at the beginning of the sentence to show its importance, while in Chinese, on the contrary, the most important information is usually placed at the end of the sentence to give people a sense of yet we called and urged a thousand times before she started toward us. When translating such texts, the translator should adjust the information structure of the translation appropriately according to the characteristics of Chinese.

Example 6: Aluminum remained unknown until the nineteenth century, because now here in nature is it found free, owing to its always being combined with other elements, most commonly with oxygen, for which it has a strong affinity.

Translation: 铝总是跟其它元素结合在一起, 最普通的是跟氧结合, 因为铝跟氧有很强的亲和力。由于这个原 因, 在自然界找不到游离状态的铝, 所以, 铝直到 19 世纪才被人发现。

Through word order adjustment, the translation conforms to the expression order of Chinese first cause and then result, and pays attention to the writing habit of semantic logic. Such a translation not only conforms to the expression habits of Chinese, but also appears clear in structure, coherent in meaning and smooth.

\section{G. Overall Coherence}

In translation practice, we usually have the feeling that if we look at a single sentence in isolation, there seems to be no problem with the translation, but if we look at the translation from the perspective of the whole text, we will feel that the translation is not coherent, logical, and confusing and awkward to read. In this case, the translator is required to consider the whole thing and adjust or reconstruct the necessary parts according to the expression habits of Chinese.

例 7: Initial trips will be within 30 feet or so from the lander, though the rover can maintain radio contact with the lander more than half a mile away.

译文: 尽管漫游者离开着陆舱半英里也能与它保持无线电联系, 但漫游者最初离开着陆舱仅限于 30 英尺左右 之内。

The translation of this sentence does not carry out literal translation in the order of the original text, but takes into account the coherence and clarity of the full text's semantics. According to the expression habits of Chinese, the clauses used as adverbial elements in the original text are advanced. Therefore, the text of the translation has very good coherence, and the semantic expression is simple, clear and understandable.

\section{CONCLUSION}

Based on Halliday's and Hasan's cohesion theory, this paper discusses several translation strategies to keep the translation coherence in EST text translation, hoping to provide some enlightenment for the research of EST text translation. Translation takes place at the level of words or sentences as well as the level of discourse, that is, focusing on the connection between sentences and sentences, paragraphs and paragraphs. The process of text translation is essentially the process of identifying and reconstructing text coherence. Whether the coherence in the original text can be reproduced and whether the communicative function of the translation can be realized depends to a great extent on the translation strategy to be adopted by the translator. Therefore, in translation practice, we must establish a clear view of the text. On the basis of fully understanding the structure of the original text, using Chinese cohesion and coherence methods flexibly to make the translation express the meaning of the original text fully and completely, and conform to the expression habits of Chinese also, be accepted by Chinese readers, ensure the accuracy of each translation, and make contributions to scientific and cultural exchanges between China and foreign countries.

\section{REFERENCES}

[1] Beau Grande, Robert de \& Dressler W. (1981). Introduction to Text Linguistics. London: Longman.

[2] Hu, Z. (1994). Cohesion and Coherence in Text. Shanghai: Shanghai Foreign Language Education Press, 112.

[3] Hu, Z., Zhu, Y. \& Zhang, D. (1988). A Survey of Systemic-Functional Grammar. Changsha: Hunan Education Publishing House.

[4] Li. Y. (2001). Introduction to Text Translation. Beijing: China Translation Corporation, 134.

[5] Liu, H. (2004). Register Constraints in Translation of Scientific English Texts. Journal of Foshan University (Social Science Edition), 3, 28-32.

[6] Ren, J. (2009). Stylistic Features of English for Science and Technology. Journal of Harbin University, 4, 30,124-126.

[7] Yu, G. (2009). Cohesive Coherence in Text and Translation. Language and Translation (Chinese Edition), 4, 47-51.

[8] Zou, W. (2003). Cohesion, Coherence and Translation. Journal of Liaoning Taxation College, 6, 32-34.

Minggao Wei was born in 1983. He is currently a postgraduate in the College of Foreign Languages, University of Shanghai for Science and Technology, Shanghai, China. His major is Master of Translation and Interpretation.

Gaofeng Yu graduated from Nankai University in 1988. He is currently an Associate Professor at University of Shanghai for Science and Technology. His research interests mainly are cognitive linguistics and translation theory and practice. 